
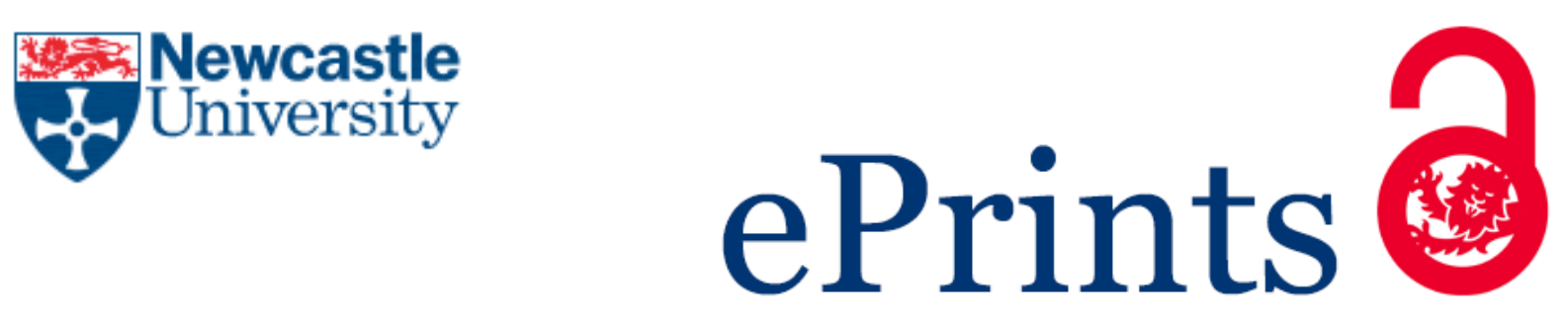

Hu Y, Schlipf J, Wussler M, Petrus ML, Jaegermann W, Bein T, MuellerBuschbaum P, Docampo P.

Hybrid Perovskite/Perovskite Heterojunction Solar Cells. ACS Nano 2016, 10(6), 5999-6007.

\title{
Copyright:
}

This document is the Accepted Manuscript version of a Published Work that appeared in final form in ACS Nano, copyright $@$ American Chemical Society after peer review and technical editing by the publisher. To access the final edited and published work see http://dx.doi.org/10.1021/acsnano.6b01535

DOI link to article:

http://dx.doi.org/10.1021/acsnano.6b01535

Date deposited:

$07 / 10 / 2016$

Embargo release date:

26 May 2017

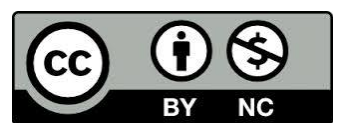

This work is licensed under a Creative Commons Attribution-NonCommercial 3.0 Unported License 


\section{Hybrid Perovskite/Perovskite Heterojunction Solar}

\section{Cells}

Yinghong Hu $u^{1}$, Johannes Schlipf ${ }^{2}$, Michael Wussler ${ }^{3}$, Michiel L. Petrus ${ }^{1}$, Wolfram Jaegermann ${ }^{3}$, Thomas Bein ${ }^{1}$, Peter Müller-Buschbaum ${ }^{2}$ and Pablo Docampo ${ }^{1, *}$

${ }^{1}$ Department of Chemistry and Center for NanoScience (CeNS), LMU Munich, Butenandtstr. 513, 81377 München, Germany.

${ }^{2}$ Physik-Department, Lehrstuhl für Funktionelle Materialien, Technische Universität München, James-Franck-Str. 1, 85748 Garching, Germany.

3 Department of Materials Science, Surface Science Division, Darmstadt University of Technology, Jovanka-Bontschits-Str. 2, 64287 Darmstadt, Germany.

CORRESPONDING AUTHOR

*P. D.: Tel: +49 (0)89 2180-77585. Fax: +49 (0)89 2180-77622.

E-mail: pablo.docampo@cup.lmu.de 


\section{ABSTRACT}

Recently developed organic-inorganic hybrid perovskite solar cells combine low-cost fabrication and high power conversion efficiency. Advances in perovskite film optimization have led to an outstanding power conversion efficiency of more than $20 \%$. Looking forward, shifting the focus

towards new device architectures holds the great potential to induce the next leap in device performance. Here, we report the first demonstration of a perovskite/perovskite heterojunction solar cell. We developed a facile solution-based cation infiltration process to deposit layered perovskite (LPK) structures onto methylammonium lead iodide (MAPI) films. Grazing-incidence wide angle X-ray scattering experiments were performed to gain insights into the crystallite orientation and the formation process of the perovskite bilayer. Our results show that the selfassembly of the LPK layer on top of an intact MAPI layer is accompanied by a reorganization of the perovskite interface. This leads to an enhancement of the open-circuit voltage and power conversion efficiency due to reduced recombination losses, as well as improved moisture stability in the resulting photovoltaic devices. Our work opens new doors to all-perovskite heterojunction architectures for highly efficient perovskite solar cells.

\section{KEYWORDS}

photovoltaic, perovskite, heterojunction, solar cell, layered compound, moisture stability 
TOC GRAPHIC

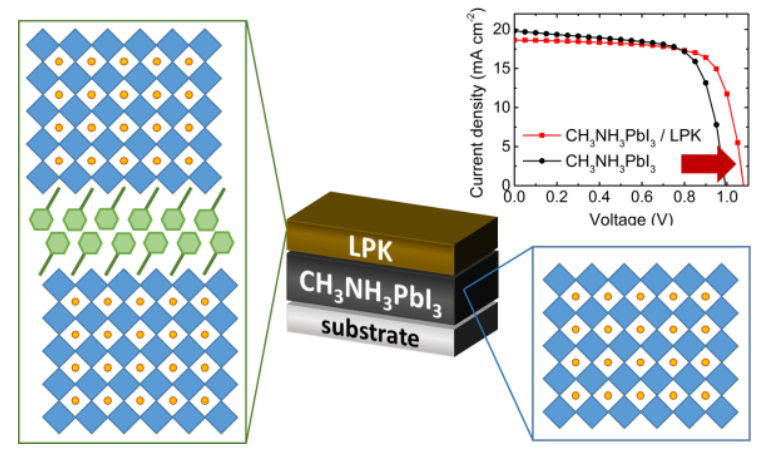


Recently, a serious contender for the established photovoltaic technologies has emerged at an unprecedented pace: organic-inorganic hybrid perovskite solar cells (PSCs). Hybrid perovskites combine low material costs, solution processability and impressive device performance. ${ }^{1-7}$ The state-of-the-art power conversion efficiency (PCE) has already exceeded 20\% in less than five years of development. ${ }^{8}$ This rapid progress has been fueled by a better understanding and control of the perovskite crystallization processes and thus, improvements to the resulting film quality. ${ }^{9-14}$ However, there is still room for improvement to reach the theoretical maximum of $31 \%$ efficiency. ${ }^{15}$ Looking forward, shifting the focus towards new device architectures holds the potential to induce the next leap in device performance.

Interfacial engineering has been proven to be a versatile tool to boost the performance of mature photovoltaic technologies, such as crystalline $\mathrm{Si}^{16}{ }^{16}$ Great efforts have been made to explore new interfacial materials for PSCs. ${ }^{17-21}$ The common device architecture is based on a $p-i-n$ heterojunction: the perovskite film is sandwiched between an electron transporter $\left(e . g\right.$. $\mathrm{TiO}_{2},{ }^{17}$ $\mathrm{PCBM}^{20,}{ }^{21}$ ) and a hole transporting layer (e.g. spiro-OMeTAD, ${ }^{22}$ PTAA, ${ }^{23}$ PEDOT:PSS ${ }^{24}$ ). Nevertheless, an all-perovskite junction with similar hybrid perovskites serving as charge extraction layers may overcome current limitations due to high conductivity and a reduction of lattice mismatch between the crystal structures. The large variety of hybrid perovskites and the ability to tune their optical and electronic properties make a perovskite/perovskite heterojunction device a likely candidate to enhance device efficiency.

An example of a highly tunable perovskite system is the re-emerging family of layered perovskites (LPKs), which has attracted considerable attention due to unique crystal structures and optoelectronic properties. ${ }^{25-30}$ By partially substituting small methylammonium cations for bulkier ones, the resulting compound resembles a multi-quantum well structure with alternating layers of 
corner-sharing lead halide octahedra and sheets of long-chained hydrophobic cations. Tailoring the bulkier cation leads to a modulation of the density of states of the material, thereby giving access to a large variety of new optoelectronic materials. To date, however, LPKs generally show poor photovoltaic performance $\left(\mathrm{PCE}<5 \%\right.$ ). ${ }^{31,32}$

Here, we have developed a facile solution process to fabricate a MAPI/LPK heterojunction that unifies the benefits of both materials: a bottom MAPI layer ensures efficient light absorption and charge generation, whereas a LPK top layer serves as selective charge extraction layer and moisture barrier. The crystal structure of the self-organized LPK incorporating methylammonium $\left(\mathrm{MA}^{+}=\mathrm{CH}_{3} \mathrm{NH}_{3}^{+}\right)$and long-chained phenylethylammonium $\left(\mathrm{PEA}^{+}=\mathrm{C}_{6} \mathrm{H}_{5} \mathrm{C}_{2} \mathrm{H}_{4} \mathrm{NH}_{3}{ }^{+}\right)$or $n$ butylammonium $\left(\mathrm{BA}^{+}=\mathrm{C}_{4} \mathrm{H}_{9} \mathrm{NH}_{3}{ }^{+}\right)$cations was determined by X-ray diffraction (XRD). Grazingincidence wide angle X-ray scattering (GIWAXS) experiments were performed to gain insights into the crystallite orientation and the formation process of the perovskite bilayer. This paper presents the demonstration of the first perovskite/perovskite heterojunction solar cell with a device performances up to $\mathrm{PCE}=16.84 \%$ due to enhanced open-circuit voltage and fill factor, complemented by enhanced moisture stability. 


\section{RESULTS AND DISCUSSION}

$\underline{\text { Film fabrication and characterization }}$

A schematic illustration of the perovskite/perovskite heterojunction is depicted in Figure 1a. To convert the top layer of the MAPI perovskite into a LPK, an isopropanol solution containing methylammonium iodide (MAI) and phenylethylammonium iodide (PEAI) or $n$-butylammonium iodide (BAI) is spin-coated onto the MAPI film.

a)

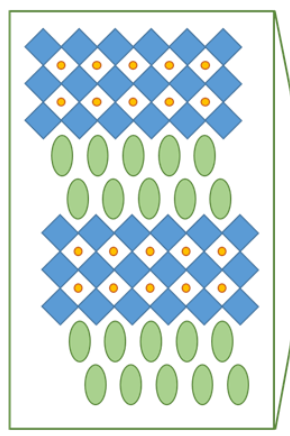

$(\mathrm{XA})_{2}(\mathrm{MA})_{\mathrm{m}-1} \mathrm{~Pb}_{\mathrm{m}} \mathrm{I}_{3 \mathrm{~m}+1}$
$\left[\mathrm{Pbl}_{6}\right]^{4-}$ octahedron

- $\mathrm{MA}=\mathrm{CH}_{3} \mathrm{NH}_{3}{ }^{+}$

$\mathrm{XA}=$ long organic cation

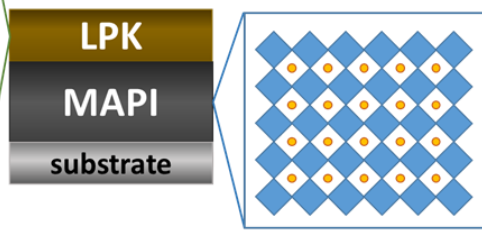

$(\mathrm{MA}) \mathrm{Pbl}_{3}$ b)

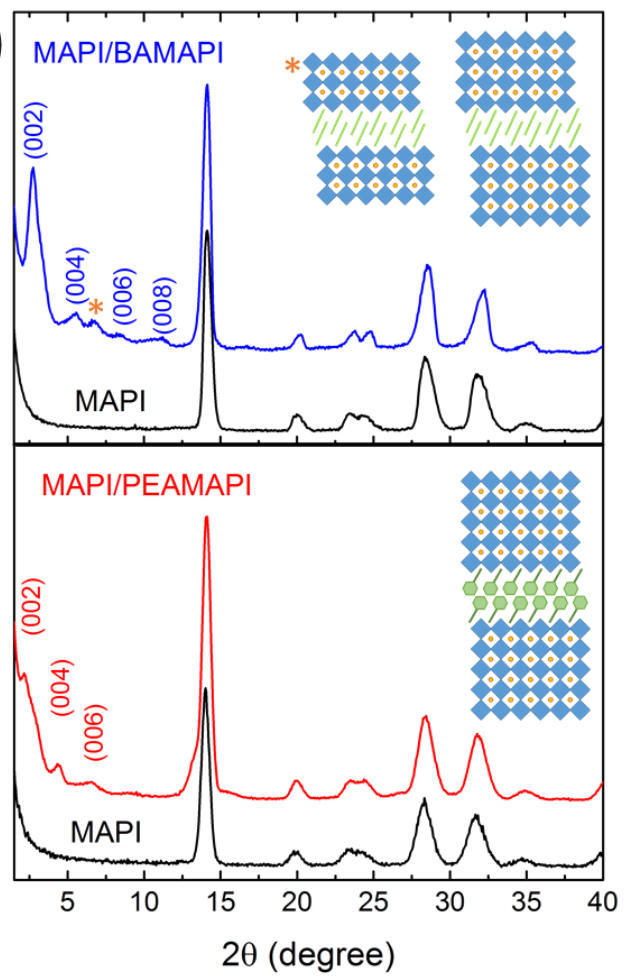

Figure 1. Structural analysis of the perovskite/perovskite heterojunction. a) Schematic illustration of the crystal structures of methylammonium lead iodide (MAPI) and a layered perovskite (LPK), forming the junction. b) XRD pattern of a MAPI film (black) compared to a MAPI/BAMAPI film (blue) and a MAPI/PEAMAPI film (red) recorded with grazing-incidence geometry. Both the MAPI bottom layer and the LPK top layer are probed with the X-ray at the incident angle of $0.5^{\circ}$. The insets show schematic representations of the corresponding LPK structure and the indexed peaks refer to expected (0OI) reflections, respectively. 
Figure $1 \mathrm{~b}$ shows the X-ray diffraction (XRD) patterns of a MAPI film before and after treatment with a PEAI:MAI or BAI:MAI solution, respectively. Besides typical diffraction peaks of the tetragonal MAPI phase, the XRD pattern of the BAI:MAI modified perovskite film exhibits several additional reflections in the $2 \theta$ range at $2.73^{\circ}, 5.56^{\circ}, 8.43^{\circ}$ and $11.17^{\circ}$. The newly emerging peaks correspond to $(00 l)$ lattice planes (with $l=2$ n) of the previously reported layered perovskite $(\mathrm{BA})_{2}(\mathrm{MA})_{3}\left(\mathrm{~Pb}_{4} \mathrm{I}_{13}\right)$ (in the following referred to as BAMAPI) ${ }^{31}$ In addition, a minor reflection appears at $2 \theta=6.81^{\circ}$ (marked with an asterisk) which can be ascribed to the (004) planes of a related LPK: $(\mathrm{BA})_{2}(\mathrm{MA})_{2}\left(\mathrm{~Pb}_{3} \mathrm{I}_{10}\right)$. We note that the formation of BAMAPI is highly sensitive to the stoichiometry of the casting solution, meaning that an excess of one of the cations can lead to the crystallization of a LPK having a different thickness of the $\left[\mathrm{PbI}_{6}\right]$ octahedra layers. In contrast, the XRD pattern of the PEAI:MAI treated MAPI film shows the signature of only one layered compound, with diffraction peaks at $2 \theta=2.16^{\circ}, 4.37^{\circ}$ and $6.53^{\circ}$, in addition to the MAPI reflections. Assuming a similar LPK structure, we can ascribe these features to the $(00 l)$ lattice planes of $(\mathrm{PEA})_{2}(\mathrm{MA})_{4}\left(\mathrm{~Pb}_{5} \mathrm{I}_{16}\right)$ (referred to as PEAMAPI) with an estimated interplanar spacing $\mathrm{d}_{002}=40.8 \AA$. Details on the estimation of the peak positions for different potential LPK structures incorporating $\mathrm{PEA}^{+}$and $\mathrm{MA}^{+}$are given in the Supporting Information (Table S1).

We fabricated MAPI/LPK bilayer films with different concentrations of the spin-coated cation mixture solution and the corresponding XRD patterns are shown in Figure S1. An increase of the overall concentration leads to higher intensities of the PEAMAPI and BAMAPI reflections with smaller peak widths, indicating the formation of a thicker LPK top layer. We performed Scherrer analysis of the most intense $(00 l)$ reflection of the LPK phase to determine the crystallite size which correlates to the thickness of the LPK top layer (see Supporting Information for details). The estimated crystallite sizes for the PEAMAPI and BAMAPI phases are summarized in Table 
S2. The increase in crystallite size with increasing concentration corroborates our hypothesis that the thickness of the self-assembled LPK layer can be tuned by the concentration of the casting solution. Besides, our results suggest that the addition of MAI to the spin-coated solution is necessary to form a pure LPK phase on top of an intact MAPI film. The absence of MAI in the solution leads to the crystallization of undesirable side phases such as PEAI (Supporting Information Figure S2).

As the MAPI/PEAMAPI system offers better control over phase purity than MAPI/BAMAPI, we chose it as a model system to study the distribution of the LPK within the mixed-perovskite film. X-ray photoelectron spectroscopy (XPS) is a powerful tool to probe the surface properties of thin films. The MAPI/PEAMAPI film and the MAPI film both exhibit a peak at $286.6 \mathrm{eV}$ in the XPS spectrum (Supporting Information Figure S3), which can be ascribed to the C1s signal of the carbon atom neighboring the $\mathrm{NH}_{3}{ }^{+}$-group in $\mathrm{MA}^{+}$. The $\mathrm{C} 1 \mathrm{~s}$ signal arising from $\mathrm{MA}^{+}$is present in the MAPI/PEAMAPI film, since methylammonium is also incorporated in the layered PEAMAPI perovskite structure. However, the MAPI/PEAMAPI sample shows an additional peak at $285.4 \mathrm{eV}$, which is likely to originate from the $\mathrm{C} 1 \mathrm{~s}$ signature of carbon atoms within the aromatic ring of the $\mathrm{PEA}^{+}$cations. As XPS is only surface-sensitive, this result confirms the formation of PEAMAPI on top of MAPI. 

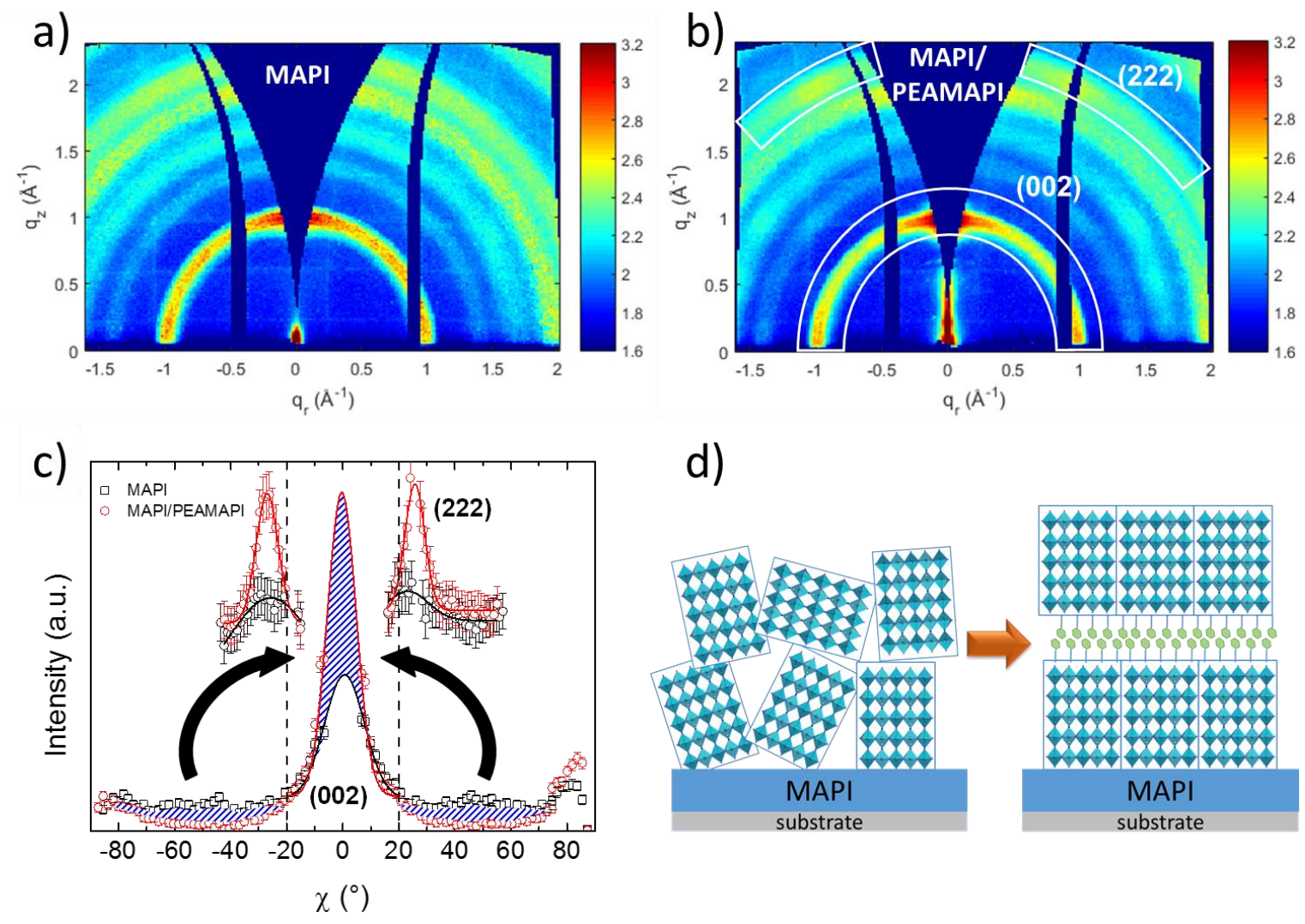

d)

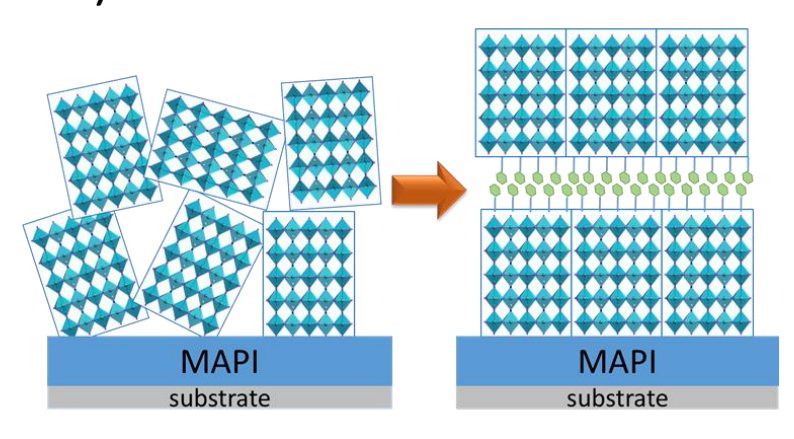

Figure 2. GIWAXS analysis for the perovskite/perovskite heterojunction. a) 2D GIWAXS pattern of a MAPI film and b) a MAPI/PEAMAPI bilayer film with highlighted (002) and (222) diffraction rings. c). Azimuthal integration around $q=1 \AA^{-1}(002)$ and $q=2.2 \AA^{-1}$ (222) for quantitative evaluation of the conversion mechanism (dashed lines indicate the $2 \sigma$ range). $d)$ Schematic interpretation of the surface reorganization of MAPI films upon PEAMAPI formation.

Furthermore, grazing incidence wide-angle X-ray scattering (GIWAXS) has been proven to be a versatile technique to elucidate the crystallization mechanism of perovskite thin films as well as its effect on solar cell performance. ${ }^{33-35}$ Here, we employed GIWAXS measurements to study the formation process of the MAPI/PEAMAPI heterojunction and to gain deeper insights into the crystallization process. Figure $2 \mathrm{a}-\mathrm{b}$ depicts the GIWAXS data obtained from a MAPI film and a MAPI/PEAMAPI perovskite bilayer film, with the in-plane component $q_{r}$ and the vertical component $q_{z}$ of the total momentum transfer $q$. Both diffraction patterns exhibit the key features 
of the tetragonal MAPI perovskite structure, represented by the broad Debye-Scherrer rings at specific $q$ values (e.g. $q=1 \AA^{-1}$ corresponding to the (002) or (110) lattice planes). However, the GIWAXS pattern of the MAPI/PEAMAPI bilayer shows two features which differ from the MAPI film: the first one appears at low $q$ values and does not form a complete ring pattern but is centered at $q_{r}=0 \AA^{-1}$. This indicates that the planes corresponding to this crystal structure are strongly oriented parallel to the substrate. We performed integration over all $q$ values (Supporting Information Figure S4) and two distinct peaks at $q \approx 0.18 \AA^{-1}$ and $0.41 \AA^{-1}$ are in agreement with the PEAMAPI peaks found in XRD and thus corroborate the formation of a highly oriented PEAMAPI phase. The second feature is visible in the change of orientation distribution along the rings formed by diffraction from the (002) and (004) planes of the tetragonal perovskite phase. The corresponding diffraction rings of the pure MAPI film (e.g. at $\left.q=1 \AA^{-1}\right)$ show a relatively homogenous azimuthal intensity distribution, indicating an isotropic orientation distribution of the crystallites. In contrast, the MAPI/PEAMAPI film exhibits a higher diffraction intensity around $q_{r}$ $=0 \AA^{-1}$, which suggests partial reorientation of crystallites upon formation of the PEAMAPI layer. Considering the high orientation of the first feature at low $q$ values we conclude that this increase in crystal orientation can be linked to the amount of PEAMAPI formed.

Provided that the increased fraction of preferentially oriented crystallites arises only from the LPK, azimuthal integration around $q=1 \AA^{-1}$ allows for quantitative evaluation of the conversion mechanism (Figure 2c): By fitting a Gaussian peak around the azimuthal angle $\chi=0^{\circ}$ and comparing differences of the areas within the $2 \sigma$ range (95\%) to the area outside this range, the amount of MAPI converted to PEAMAPI is determined as 7\%. The use of a Gaussian peak shape to amend the data in the inaccessible range around $\chi=0^{\circ}$ is justified by comparison to an integration of the (222) peak (see Supporting Information for more details on the estimation). The 
beam footprint covers the entire sample at the incident angle of $0.4^{\circ}$ and thus probes the same sample volume in both measurements. Consequently, the calculated difference directly translates to $7 \%$ of the film thickness or about $20 \mathrm{~nm}$ of PEAMAPI, equivalent to 4-5 layers of the LPK compound. This result is in very good agreement with the determined film thickness of PEAMAPI estimated from the Scherrer analysis of the (006) diffraction peak (see Table S2).

The above analysis assumes a more or less perfect orientation of the LPK layer parallel to the substrate. This assumption is justified by the following considerations: Spin-coating a PEAI:MAI solution from isopropanol presumably leads to a reorganization of the MAPI top layer, accompanied by fast de-intercalation of MAI and intercalation of PEAI into the perovskite structure. $\mathrm{PEA}^{+}$cations form extended organic sheets due to steric effects, $\pi$-stacking of the phenyl-rings, and hydrogen-bonding interactions between the $\mathrm{NH}_{3}{ }^{+}$-group with the neighboring $\left[\mathrm{PbI}_{6}\right]$ octahedra layer, respectively. ${ }^{26,27,36}$ It has been shown that long-chained organic cations can act as a template for the extremely anisotropic growth of LPK crystals, resulting in films with a strong preferential crystal orientation. ${ }^{31,37,38}$ In this case, the inorganic $\left[\mathrm{PbI}_{6}\right]$ octahedra layer sandwiched between two organic layers is thus confined parallel to the substrate (as illustrated in Figure 2d). This reorganization of the perovskite structure gives rise to the intensity increase around $\chi=0^{\circ}$ in the GIWAXS pattern of the MAPI/PEAMAPI film.

The integrity of the MAPI bottom layer is essential to justify our concept of a perovskite/perovskite heterojunction. Due to the size of $\mathrm{PEA}^{+}$and $\mathrm{BA}^{+}$, these organic molecules are too large to be incorporated into the perovskite structure replacing $\mathrm{MA}^{+}$, and can only form layered compounds. However, any distortion in the MAPI lattice by percolated $\mathrm{PEA}^{+}$or $\mathrm{BA}^{+}$ cations would be visible in the XRD patterns. As both standard wide-angle XRD and GIWAXS measurements indicate the existence of only two crystal phases - pristine MAPI and the layered 
perovskite - we do not expect compositional changes within the MAPI bottom layer. Therefore, the term "perovskite/perovskite heterojunction" is justified.

\section{Device performance}

We fabricated planar heterojunction perovskite solar cells comprising a MAPI/PEAMAPI or MAPI/BAMAPI perovskite heterojunction. The final device configuration is glass/FTO/compact $\mathrm{TiO}_{2} /$ perovskite/spiro-OMeTAD/Au. A cross-sectional SEM image of a MAPI/PEAMAPI perovskite solar cell is depicted in Figure 3a. 

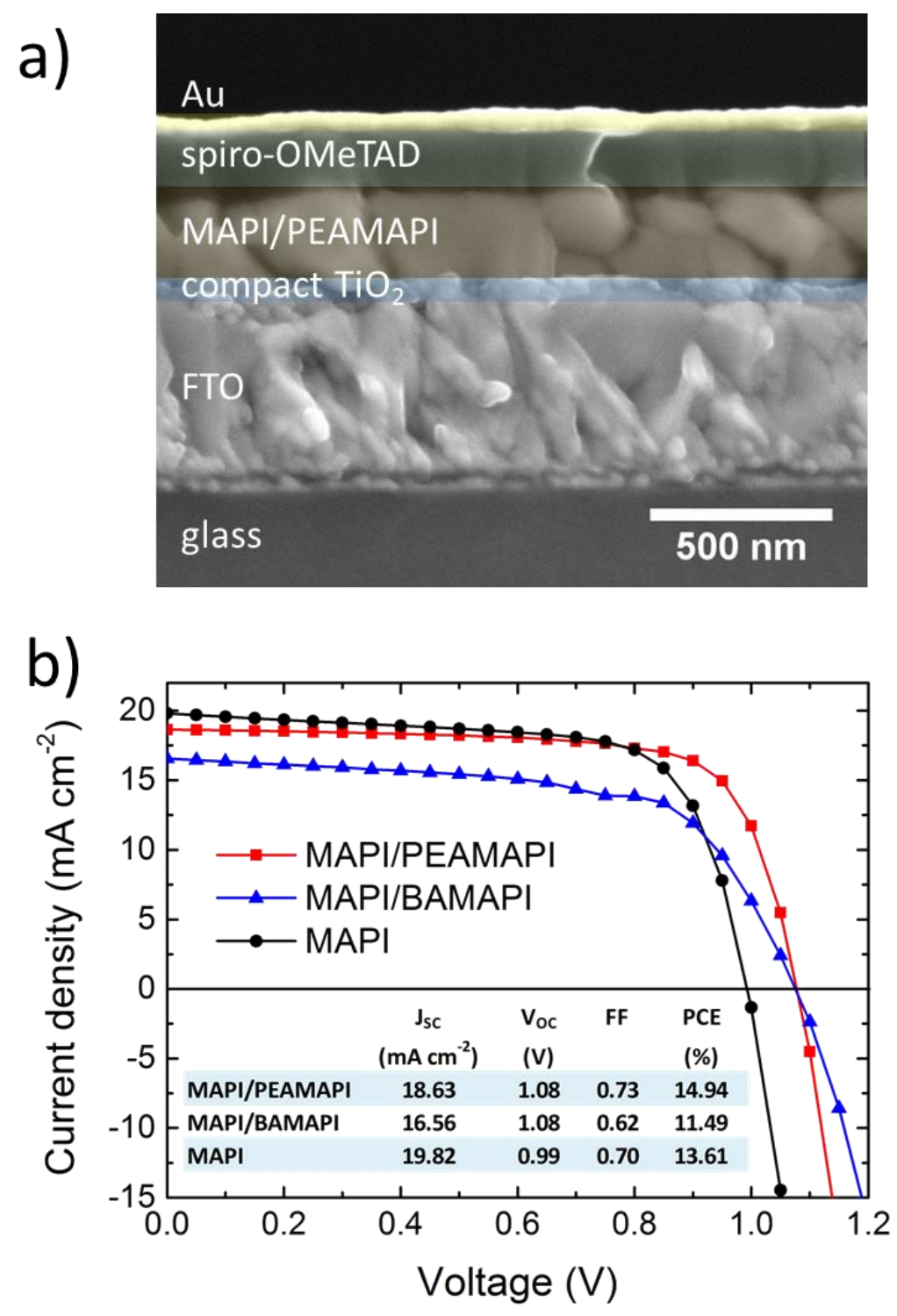

Figure 3. a) SEM cross-section of a MAPI/PEAMAPI planar heterojunction solar cell. b) J-V curves and characteristics of the best-performing devices comprising different perovskite layer configurations. Both MAPI/LPK heterojunction devices incorporate a 20-25 nm thick LPK top layer. Recorded under one sun AM $1.5 \mathrm{G}$ illumination at reverse bias sweep with a scan rate of $0.5 \mathrm{~V} \mathrm{~s}^{-1}$. The inset table indicates the determined performance parameters for each type of device.

Figure $3 \mathrm{~b}$ presents the current-voltage $(J-V)$ curves of a MAPI/BAMAPI, MAPI/PEAMAPI, and a MAPI-based solar cells recorded under simulated air mass (AM) 1.5G solar illumination by scanning the voltage from $2 \mathrm{~V}$ to $0 \mathrm{~V}$. Both perovskite bilayer devices give significantly higher 
open-circuit voltages $\left(V_{\mathrm{OC}}\right)$ of $1.08 \mathrm{~V}$ than the device composed of pristine MAPI $\left(V_{\mathrm{OC}}=0.99 \mathrm{~V}\right)$. The short-circuit current density $\left(J_{\mathrm{SC}}\right)$ of the MAPI/PEAMAPI-based device is slightly lower $\left(J_{\mathrm{SC}}=18.63 \mathrm{~mA} / \mathrm{cm}^{2}\right)$ compared to the reference cell $\left(J_{\mathrm{SC}}=19.82 \mathrm{~mA} / \mathrm{cm}^{2}\right)$, whereas the MAPI/BAMAPI cell suffers a more pronounced drop in photocurrent density $\left(J_{\mathrm{SC}}=\right.$ $16.56 \mathrm{~mA} / \mathrm{cm}^{2}$ ). Ultimately, the resulting power conversion efficiency of the MAPI/PEAMAPI device $(\mathrm{PCE}=14.94 \%)$ is improved compared to the non-treated MAPI cell $(\mathrm{PCE}=13.61 \%)$, while the MAPI/BAMAPI device yields $11.49 \%$. By utilizing a further optimized perovskite deposition protocol, a $16.84 \%$ MAPI/PEAMAPI cell with $V_{\mathrm{OC}}=1.11 \mathrm{~V}$ was obtained. The corresponding $J-V$ curves and the stabilized power output are given in the Supporting Information Figure S5-6.

The formation of an optimized LPK top layer has two effects on the photovoltaic performance: a slight decrease in short-circuit current density and an increase in open-circuit voltage. The loss in $J_{\mathrm{SC}}$ can be attributed to two factors: firstly, charge transport is inhibited by the organic interlayers within the LPK film which are in our samples perpendicularly oriented to the direction of charge transport. With increasing thickness of the LPK layer, photo-generated charge carriers need to overcome a larger number of electronically insulating sheets formed by the bulky organic cations. This is evidenced by the dramatic loss in $J_{\mathrm{SC}}$ for devices prepared with higher concentrations of the PEAI:MAI casting solution (Supporting Information Figure S7). Also the MAPI/BAMAPIbased solar cell (BAMAPI with $\mathrm{m}=3$ and $\mathrm{m}=4$ ) is composed of a larger number of organic interlayers than the MAPI/PEAMAPI $(m=5)$ device with the same total LPK film thickness, thus leading to a larger drop in $J_{\mathrm{SC}}$ (Figure $3 \mathrm{~b}$ ). Secondly, the light absorption spectrum of a MAPI/PEAMAPI film reveals a slight decrease in absorbance compared to a pristine MAPI film (Supporting Information Figure S8), as partial conversion into the LPK occurs. The loss in light 
absorption also contributes to the decrease in $J_{\mathrm{SC}}$. Further studies were conducted on the MAPI/PEAMAPI system, which incorporates only a single phase LPK and demonstrates a higher photovoltaic performance than MAPI/BAMAPI-based devices.

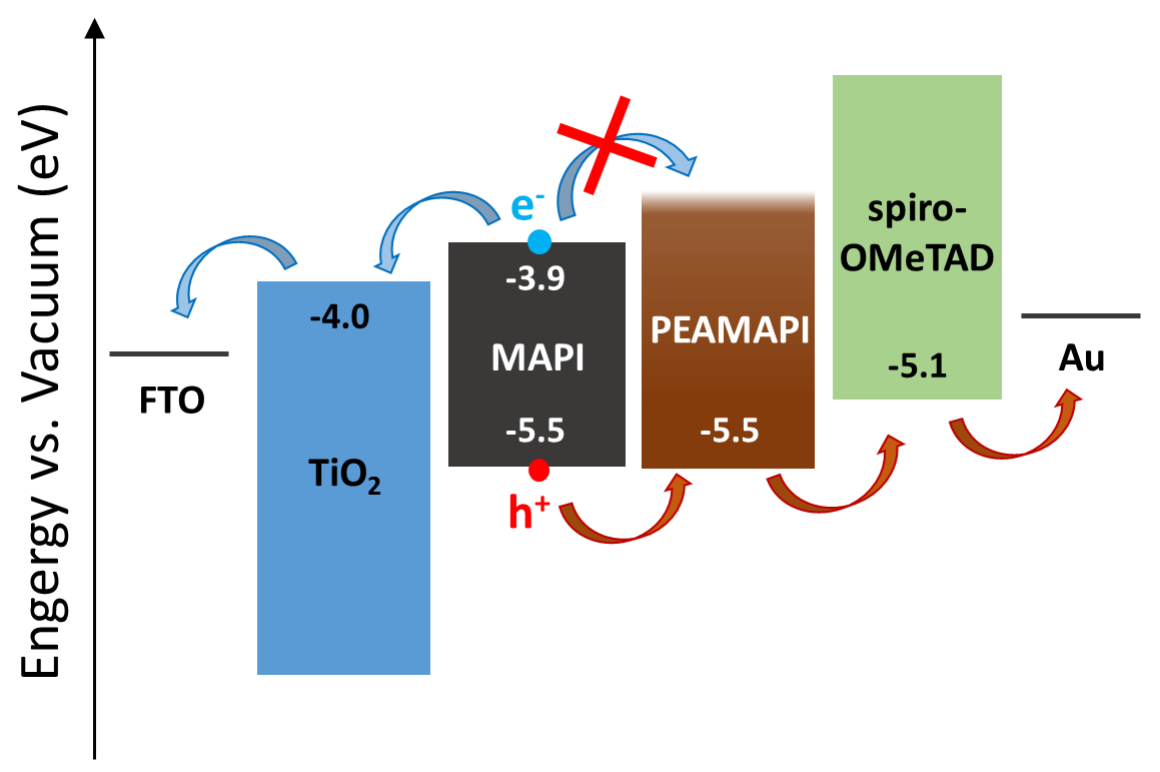

Figure 4. Schematic energy level diagram of a MAPI/PEAMAPI heterojunction solar cell.

The second effect of the PEAMAPI layer is an enhancement of $V_{\mathrm{OC}}$ and FF. It has been previously reported that an increase in $V_{\mathrm{OC}}$ and $\mathrm{FF}$ can be linked to a reduction in charge recombination rates through optimizing charge-selective contact materials. ${ }^{39,40}$ To investigate if this occurs in our perovskite/perovskite heterojunction, we examined the energy level alignment between MAPI and PEAMAPI by XPS measurements. The thickness of the optimized PEAMAPI top layer is around 20-22 nm, as estimated via GIWAXS experiments and Scherrer analysis (see Table S2). The recorded XPS results of a MAPI/PEAMAPI sample can therefore be attributed to 
the PEAMAPI material. Figure S9 shows that the valence band onset for MAPI and PEAMAPI are located at the same energy level and both samples exhibit comparable work functions. Bandgap estimations for the new PEAMAPI compound is difficult, as the absorption profile of MAPI predominates the absorption spectrum of the MAPI/PEAMAPI sample (Supporting Information Figure S8). However, Cao et al. ${ }^{31}$ showed that the introduction of long-chained cations into the MAPI structure increases the bandgap of the perovskite material. Accordingly, we expect PEAMAPI to exhibit a wider bandgap than MAPI. Electronically speaking, this means that the valence bands of PEAMAPI and MAPI are well aligned and that the conduction band onset for PEAMAPI should be energetically higher. Electron transfer from MAPI to PEAMAPI would thus be uphill in energy and is inhibited (Figure 4). Charge recombination at the interface is further reduced with the LPK layer acting as a selective hole extraction layer between MAPI and spiroOMeTAD, explaining our observed change in $V_{\mathrm{OC}}$ and FF.

Further evidence towards this hypothesis is given by time-resolved photoluminescence (PL) spectroscopy. This technique provides an insight into the recombination dynamics of photogenerated electron-hole pairs by monitoring the PL decay as a function of time. We evaluated the PL lifetime of MAPI and MAPI/PEAMAPI films by time-correlated single photon counting (TCSPC). The decrease in PL lifetime of the MAPI/PEAMAPI sample suggests PL quenching by the LPK layer, which supports the notion of hole transfer from MAPI into PEAMAPI (Supporting Information Figure S10). With this information in hand, we assign the increase in $V_{\mathrm{OC}}$ and FF observed for devices incorporating a MAPI/PEAMAPI heterojunction to a reduction in charge recombination rates. Moreover, the reorganization of the MAPI film surface upon $\mathrm{PEA}^{+}$insertion evidenced by the GIWAXS data is likely to reduce surface recombination, possibly also contributing to the observed increase in $V_{\mathrm{OC}}$ and $\mathrm{FF}$. 
In order to verify the reproducibility of the $J-V$ curve results, we evaluated the performance of 156 MAPI/PEAMAPI solar cells and 156 MAPI reference cells fabricated from different batches on different days. Figure 5 shows the statistical distribution of $V_{\mathrm{OC}}, J_{\mathrm{SC}}, \mathrm{FF}$ and $\mathrm{PCE}$ values for both types of devices. The findings are in good agreement with our observations from the champion cells.
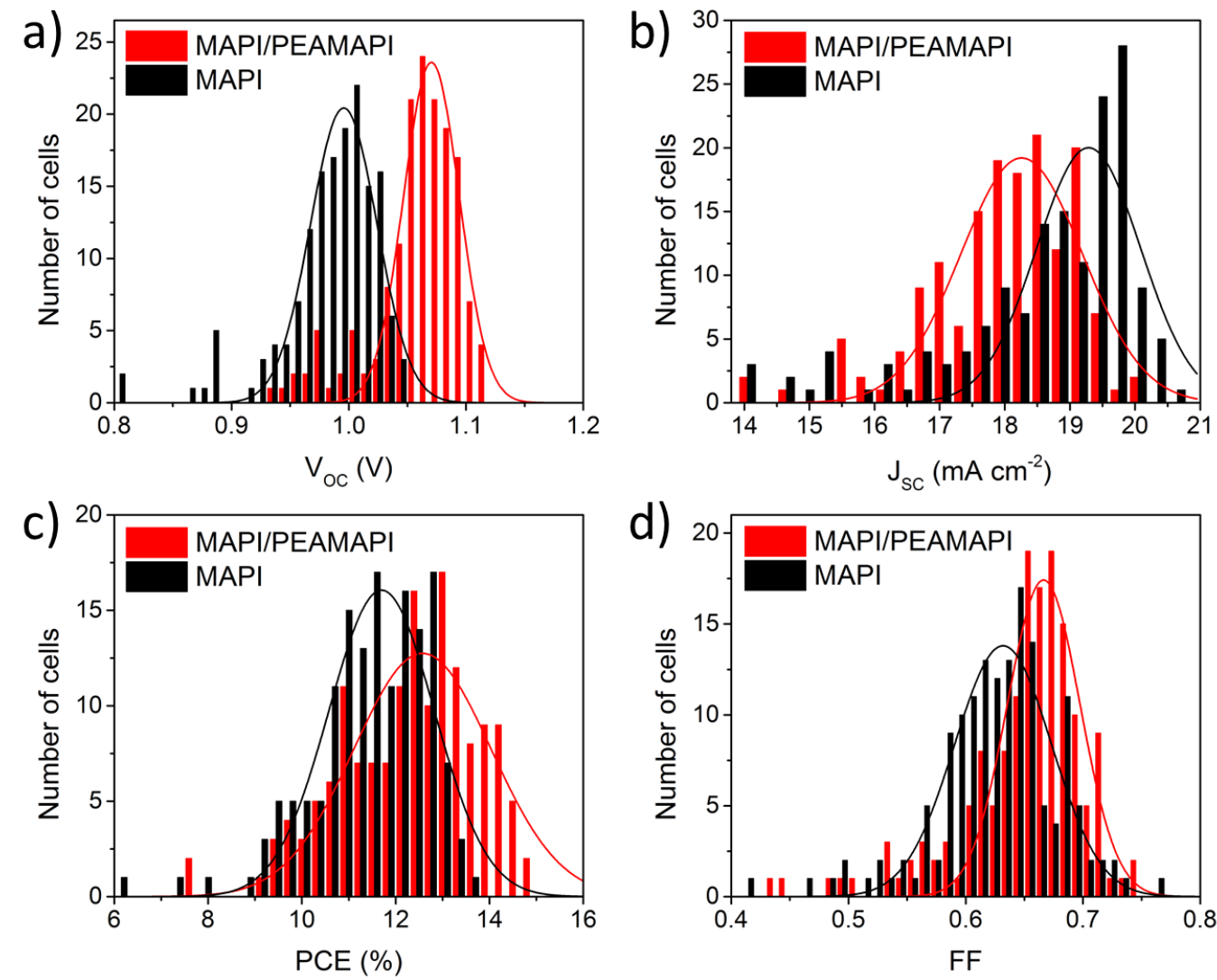

Figure 5. Statistical evaluation of the J-V data (reverse bias scans from $2 \mathrm{~V}$ to $0 \mathrm{~V}$ ) obtained for 156 MAPI/PEAMAPI devices and 156 MAPI devices. Comparison of a) open-circuit voltage $\left.\left(V_{o c}\right), b\right)$ shortcircuit current density $\left.\left(J_{S C}\right), c\right)$ power conversion efficiency $(P C E)$ and d) fill factor (FF).

Planar perovskite solar cells are notorious for their anomalous hysteresis in $J-V$ measurements, i.e. the $J-V$ curve obtained from the forward bias scan (from $0 \mathrm{~V}$ to $2 \mathrm{~V}$ ) differs from the one 
obtained from the reverse bias scan (from $2 \mathrm{~V}$ to $0 \mathrm{~V}$ ). This phenomenon is usually assigned to ion migration within the perovskite layer. ${ }^{41-44}$ We observed typical hysteretic behavior for MAPI and MAPI/LPK devices to approximately the same degree (Supporting Information Figure S11). By partially substituting $\mathrm{MA}^{+}$for the bulkier organic cations, less mobile ionic species are in the perovskite lattice, which should induce less hysteresis in the perovskite/perovskite heterojunction devices. However, in our optimized devices, only $7 \%$ of the original MAPI film is converted into the layered perovskite, while a thick MAPI bottom layer $(\sim 250 \mathrm{~nm})$ is maintained. Due to this fact, we do not observe a significant reduction of the usual hysteresis caused by ion migration.

In addition to the pursuit of better performing devices, ensuring the long-term stability of PSCs remains a major challenge. In particular, hybrid perovskites are known to be chemically unstable in the presence of moisture. Recently, it has been shown that LPKs incorporating hydrophobic long-chain organic cations are more resistant towards humidity-induced degradation. ${ }^{32}$ Here, we studied the moisture stability of MAPI/PEAMAPI perovskite solar cells by exposing devices without any encapsulation to air at constant $75 \%$ relative humidity (RH) in a sealed container at room temperature.

Figure 6a presents the PCE of 20 MAPI cells and 20 MAPI/PEAMAPI cells before and after exposure to humid air at 75\% RH. After 19 days, MAPI/PEAMAPI devices exhibit a significantly higher average efficiency $(\mathrm{PCE}=11.4 \%)$ than the MAPI reference cells $(6.1 \%)$. Strong decolorization of the MAPI solar cell indicates advanced degradation of the perovskite film, whereas the MAPI/PEAMAPI bilayer cell maintained the dark brown color of an intact perovskite absorber layer. Additional reflections in the XRD pattern of the degraded MAPI-based device originate from a MAPI hydrate $\left(\mathrm{CH}_{3} \mathrm{NH}_{3} \mathrm{PbI}_{3} \cdot \mathrm{H}_{2} \mathrm{O}\right)^{45}, 46$ and $\mathrm{PbI}_{2}$ (Figure 6b), indicating the decomposition of the perovskite layer. In contrast, no degradation products can be identified in the 
XRD pattern of the MAPI/PEAMAPI device. In order to monitor the diffraction peaks of PEAMAPI before and after hydration, we prepared MAPI/PEAMAPI and pure MAPI samples on glass which were analyzed in grazing-incidence geometry at an incident angle of $0.5^{\circ}$. The corresponding XRD patterns (Supporting Information Figure S12) reveal that the MAPI sample shows degradation upon hydration at $75 \% \mathrm{RH}$ for $2 \mathrm{~h}$, whereas the MAPI/PEAMAPI sample does not show structural changes or degradation products. Our results verify the effect of the LPK top layer as a moisture barrier, which correlates with an improvement in device stability towards exposure to a high level of humidity.
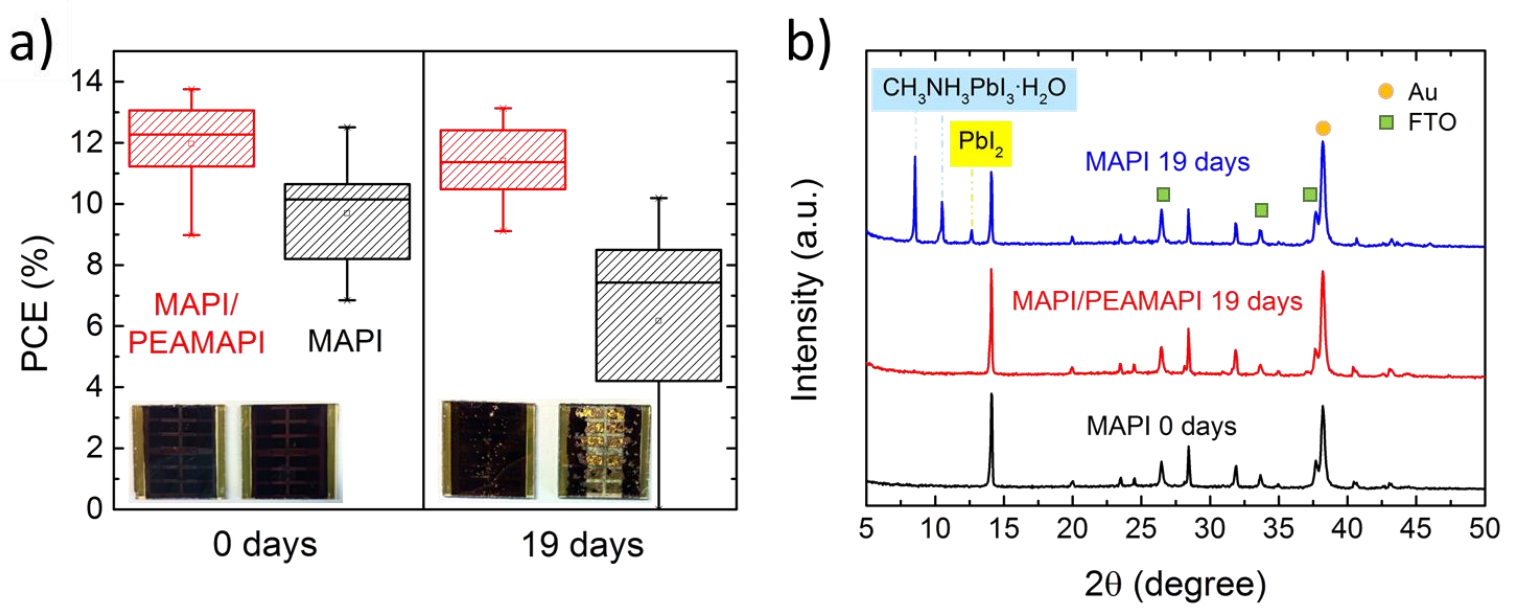

Figure 6. Device stability test at $75 \%$ RH in air at room temperature for 19 days. a) Efficiency distribution for $20 \mathrm{MAPI} / P E A M A P I$ and $20 \mathrm{MAPI}$ devices before and after exposure to humidity. The insets show the corresponding photograph of a MAPI/PEAMAPI cell (left) compared to a MAPI control cell (right). b) XRD patterns of an intact MAPI cell, a MAPI/PEAMAPI cell and a MAPI cell upon exposure to moisture. 


\section{CONCLUSION}

To conclude, this paper shows that a perovskite/perovskite heterojunction architecture comprising MAPI and a layered perovskite compound can be fabricated via a solution-based cation infiltration process. The successful realization of two MAPI/LPK heterojunction systems incorporating different long-chained organic cations proves the versatility of the novel deposition method developed here. GIWAXS experiments reveal the preferential growth of the layered PEAMAPI perovskite, which is accompanied by a reorganization and reorientation of the MAPI top layer. We demonstrate that photovoltaic devices based on a MAPI/PEAMAPI heterojunction reach power conversion efficiencies of up to $16.84 \%$ due to an increase in open-circuit voltage and fill factor. Our results indicate that the LPK top layer may act as a selective charge extraction layer for MAPI perovskite, leading to reduced recombination losses within the device. With an optimized LPK layer thickness, the detrimental effects of the organic barriers on the charge transport and light absorption is compensated by the enhanced $V_{\mathrm{OC}}$ and FF. In addition, the enhancement in device stability towards exposure to moisture implies prolonged device lifetime, which is a crucial aspect for the implementation of perovskite-based photovoltaics in outdoor applications. The immense variety of organic cations that can be incorporated into the perovskite structure offers numerous possibilities to fine-tune and control the interface; from energy level alignment for graded band gap structures to the chemical stability of the system. ${ }^{26,32,36,47,48}$ Our results open new pathways to assemble and tailor perovskite/perovskite heterojunctions. We believe that this novel approach holds great potential to improve device stability and to break new efficiency records for this class of solar cells. 


\section{METHODS}

\section{$\underline{\text { Synthesis of Organic Cation Salts }}$}

PEAI crystals were synthesized by dropwise adding a solution of HI (Sigma-Aldrich, 57 wt $\%$ in water, $27 \mathrm{~mL}, 204 \mathrm{mmol})$ to a cold $\left(0^{\circ} \mathrm{C}\right)$ mixture of 2-phenylethylamine (Sigma-Aldrich, $25 \mathrm{~mL}$, $198 \mathrm{mmol})$ and absolute ethanol $(25 \mathrm{~mL})$ under stirring. The colorless precipitate was collected by suction filtration and washed several times with diethyl ether. After recrystallization from isopropanol and drying under reduced pressure, colorless PEAI crystals were obtained. To synthesize BAI crystals, $n$-butylamine (Acros, 99.5\%) was reacted with HI in the same way as

described above for the PEAI synthesis. MAI crystals were obtained by adding an aqueous HI solution (10 mL, $76 \mathrm{mmol})$ dropwise to $24 \mathrm{~mL}$ (193 mmol) methylamine solution (Sigma-Aldrich, $33 \mathrm{wt} \%$ in absolute ethanol) diluted in $100 \mathrm{~mL}$ absolute ethanol at $0{ }^{\circ} \mathrm{C}$ under stirring. After further stirring for $2 \mathrm{~h}$ at room temperature, the solvent was removed at $45^{\circ} \mathrm{C}$ by using a rotary evaporator and the colorless precipitate was recrystallized from absolute ethanol. Finally, the colorless MAI crystals were filtrated, washed with diethyl ether and dried overnight under vacuum.

\section{$\underline{\text { Thin Film Preparation }}$}

Thin films of methylammonium lead iodide (MAPI) were prepared in a glovebox under dry nitrogen atmosphere, by following a protocol reported by Xiao et al. ${ }^{49}$ First, clean glass substrates $\left(2.5 \times 2.5 \mathrm{~cm}^{2}\right)$ were treated in a plasma-cleaner with oxygen plasma for $5 \mathrm{~min}$. MAI $(0.4 \mathrm{~g}, 2.5$ mmol) and $\mathrm{PbI}_{2}$ (Sigma-Aldrich, 99\%, $1.156 \mathrm{~g}, 2.5 \mathrm{mmol}$ ) were dissolved in $2 \mathrm{~mL} N, N-$ dimethylformamide (DMF, Sigma-Aldrich, anhydrous) under stirring at $100{ }^{\circ} \mathrm{C}$. The yellow solution was cooled down and filtrated through a $0.45 \mu \mathrm{m}$ syringe filter, affording a $1.25 \mathrm{M}$ precursor solution of MAPI. Then $75 \mu \mathrm{L}$ perovskite solution was dynamically spin-coated on a 
clean glass substrate at $5000 \mathrm{rpm}$ for $30 \mathrm{~s}$. With a delay time of $4-5 \mathrm{~s}, 200 \mu \mathrm{L}$ chlorobenzene (Sigma-Aldrich, anhydrous) was quickly introduced to the spinning film in order to promote MAPI crystallization. The sample was annealed on a hotplate at $100{ }^{\circ} \mathrm{C}$ for $10 \mathrm{~min}$ to remove residual solvents. Finally, homogeneous, dark-brown MAPI films were obtained. The conversion of the top layer of a MAPI thin film into the layered PEAMAPI perovskite structure was achieved by spin-coating an equimolar mixture of phenylethylammonium iodide (PEAI) and methylammonium iodide (MAI) in isopropanol (IPA, Sigma, anhydrous). PEAI and MAI were dissolved in isopropanol with different concentrations varying from $5 \mathrm{mM}$ to $40 \mathrm{mM}$ (the molarity refers to both PEAI and MAI). Subsequently, $75 \mu \mathrm{L}$ PEAI:MAI solution was spin-coated on a MAPI film at $4000 \mathrm{rpm}$ for $45 \mathrm{~s}$ and the films were annealed at $70{ }^{\circ} \mathrm{C}$ for $5 \mathrm{~min}$ to remove residual solvents. The preparation of MAPI/BAMAPI films followed the same protocol, using an equimolar solution of BAI and MAI dissolved in IPA.

\section{$\underline{\text { Solar Cell Fabrication }}$}

For the device fabrication, FTO (fluorine-doped tin oxide) coated glass slides (Pilkington, 7 $\Omega /$ sq) were employed as substrates. The substrates were patterned by etching with zinc powder and $3 \mathrm{M} \mathrm{HCl}$ solution and successively cleaned with deionized water, a 2\% Hellmanex detergent solution, acetone, ethanol and finally treated with oxygen plasma for $5 \mathrm{~min}$. $\mathrm{A}_{\mathrm{TiO}}$ compact layer was deposited as hole blocking layer on the substrate via a sol-gel approach. For this purpose, a mixture of $2 \mathrm{M} \mathrm{HCl}(35 \mu \mathrm{L})$ and anhydrous IPA $(2.53 \mathrm{~mL})$ was added dropwise to a solution of $370 \mu \mathrm{L}$ titanium(IV) isopropoxide (Sigma-Aldrich) in IPA $(2.53 \mathrm{~mL})$ under vigorous stirring. The clear $\mathrm{TiO}_{\mathrm{x}}$ solution was spin-coated dynamically on the clean FTO substrates at $2000 \mathrm{rpm}$ for $45 \mathrm{~s}$, followed by annealing at $150{ }^{\circ} \mathrm{C}$ for $10 \mathrm{~min}$ on a hotplate. $\mathrm{The} \mathrm{TiO}_{2}$ compact layer was completed by sintering at $500{ }^{\circ} \mathrm{C}$ in air for $45 \mathrm{~min}$ and the final substrates were cut into pieces of $3 \times 3 \mathrm{~cm}^{2}$. 
The deposition of the MAPI absorber layer and its partial conversion into PEAMAPI or BAMAPI was processed in a nitrogen-filled glovebox as described above for the thin film preparation.

For the fabrication of the best performing devices, a further optimized procedure for the MAPI film deposition was used. Here, a 1.2 M solution of $\mathrm{PbI}_{2}$ (TCI, 98\%) and MAI in a 4:1 (vol:vol) mixture of DMF and DMSO was deposited in a consecutive two-step spin-coating process at $1000 \mathrm{rpm}$ and $5000 \mathrm{rpm}$ for $10 \mathrm{~s}$ and $30 \mathrm{~s}$, respectively. Approximately $15 \mathrm{~s}$ before the end of spinning, $500 \mu \mathrm{L}$ of chlorobenzene was added to the film. After annealing the substrates at $100{ }^{\circ} \mathrm{C}$ for 10 min on a hotplate, MAPI films were formed. The generation of the PEAMAPI top layer by spin-coating a $10 \mathrm{mM}$ PEAI:MAI (1:1) solution followed the same protocol as described above.

For the deposition of the hole transporter layer, a solution of 2,2',7,7'-tetrakis-( $N, N$-di- $p$ methoxyphenyl-amine)-9,9'-spirobifluorene (spiro-OMeTAD) in anhydrous chlorobenzene ( $75 \mathrm{mg} / \mathrm{mL}$ ) was filtered through a $0.45 \mu \mathrm{m}$ syringe filter. Then $10 \mu \mathrm{L}$ 4-tert-butylpyridine (SigmaAldrich, $96 \%$ ) and $30 \mu \mathrm{L}$ of a $170 \mathrm{mg} / \mathrm{mL}$ lithium bistrifluoromethanesulfonimidate (SigmaAldrich, 99.95\%) solution in acetonitrile (Sigma-Aldrich, anhydrous) were added to $1 \mathrm{~mL}$ spiroOMeTAD solution. The hole-transporting material was deposited on the device substrate by spincoating at $2000 \mathrm{rpm}$ for $45 \mathrm{~s}$. The samples were stored overnight in a desiccator under air atmosphere with $\sim 21 \%$ relative humidity. Finally, a $40 \mathrm{~nm}$ Au layer was deposited through a patterned shadow mask by thermal evaporation at $4 \cdot 10^{-6}$ mbar and a deposition rate of $0.1 \mathrm{~nm} / \mathrm{s}$ in order to form the back electrode.

\section{Film Characterization:}

X-ray diffraction (XRD) measurements of thin films were performed with a Bruker D8 Discover X-ray diffractometer operating at $40 \mathrm{kV}$ and $30 \mathrm{~mA}$, employing Ni-filtered $\mathrm{Cu} \mathrm{K} \alpha 1$ radiation 
$(\lambda=1.5406 \AA)$ and a position-sensitive LynxEye detector. The Bragg-Brentano scanning geometry or an alternative grazing-incidence geometry with an incident angle of $0.5^{\circ}$ was applied to record the data. Powder X-ray diffraction (PXRD) patterns were recorded on a STOE powder diffractometer equipped with a position-sensitive Mythen-1K detector in transmission geometry.

Grazing-incidence wide angle X-ray scattering (GIWAXS) measurements were conducted under vacuum using a Ganesha 300XL SAXS-WAXS system with a $\mathrm{Cu} \mathrm{K}_{\alpha}$ source. The samples were carefully aligned with a diode before each measurement and the scattering signal was recorded with a Pilatus 300k detector (Dectris). The incident angle was $\alpha_{I}=0.4^{\circ}$ and the sample-detector distance (SDD) was around $110 \mathrm{~mm}$. The SDD was calibrated for each measurement individually using XRD data. The software GIXSGUI was used for data treatment and evaluation using the various corrections offered by the software.

X-ray photoelectron spectroscopy (XPS) data were collected at a PHI Versaprobe II system at a pressure of $10^{-9}$ mbar. Monochromatic Al- $\mathrm{K}_{\alpha}$ radiation $(1486.6 \mathrm{eV})$ and a hemispherical analyzer with a pass energy of $11.75 \mathrm{eV}$ for $\mathrm{C} 1 \mathrm{~s}$ and $23.5 \mathrm{eV}$ for the valence region were used. The binding energies were calibrated at the Fermi-edge $(0 \mathrm{eV})$ and $\mathrm{Ag} 3 \mathrm{~d}_{5 / 2}(368.26 \mathrm{eV})$ on a sputtered silver reference. All spectra show photoemission in normal direction. The samples were exposed to ambient illumination during the measurement. The work function was determined by analyzing the secondary electron edge under He I $(21.22 \mathrm{eV})$ illumination and an applied bias voltage of $3 \mathrm{~V}$. A pass energy of $5.85 \mathrm{eV}$ was used for the detector.

Scanning electron microscopy (SEM) images were recorded with a JEOL JSM-6500F scanning electron microscope, operated at an acceleration voltage of $5 \mathrm{keV}$. 
Ultraviolet-visible (UV-Vis) absorption spectra were recorded using a Perkin Elmer Lambda 1050 spectrophotometer equipped with a $150 \mathrm{~mm}$ integrating sphere. Air (100\% transmission) and a Spectralon white standard (100\% reflection) were used for the instrument baseline.

Time-resolved photoluminescence (PL) spectroscopy was performed with a Fluotime 300 spectrofluorometer (Picoquant). The excitation wavelength was fixed at $510 \mathrm{~nm}$ and TCSPC data were collected by monitoring the PL emission maximum around $770 \mathrm{~nm}$.

\section{Device Characterization}

Current-Voltage $(J-V)$ characteristics of the perovskite solar cells were measured in air at ambient conditions using a Newport OrielSol 2A solar simulator with a Keithley 2401 source meter. The devices were illuminated through a shadow mask, yielding an active area of 0.0813 $\mathrm{cm}^{2}$. The $J-V$ curves were recorded under standard AM $1.5 \mathrm{G}$ solar illumination from a $450 \mathrm{~W}$ xenon lamp, calibrated to a light intensity of $100 \mathrm{~mW} \mathrm{~cm}^{-2}$ with a Fraunhofer ISE certified silicon diode (KG5-filtered). A spectral mismatch factor of 1.002 was estimated following a previously established protocol..$^{50}$ Prior to each measurement, the cell was pre-biased at $2 \mathrm{~V}$ for $10 \mathrm{~s}$ under illumination. The input bias voltage was scanned from $2 \mathrm{~V}$ to $0 \mathrm{~V}$ (referred to as reverse scan) in $0.05 \mathrm{~V}$ steps with a scan rate of $0.5 \mathrm{~V} \mathrm{~s}^{-1}$ and then from 0 to $2 \mathrm{~V}$ (forward scan) at the same scan rate. Devices fabricated according to the optimized protocol for the MAPI film deposition were pre-biased at $1.5 \mathrm{~V}$ for $10 \mathrm{~s}$ under illumination and the voltage was scanned in reverse ( $1.5 \mathrm{~V}$ to 0 $\mathrm{V})$ and forward direction $(0 \mathrm{~V}$ to $1.5 \mathrm{~V})$ in $0.01 \mathrm{~V}$ steps with a scan rate of $0.1 \mathrm{~V} \mathrm{~s}^{-1}$. For the maximum power aging measurements, the voltage was held constant at the maximum power voltage and the PCE was monitored over a period of $20 \mathrm{~s}$.

\section{$\underline{\text { Stability Test }}$}


Humidity studies on the perovskite solar cells were conducted in a shaded glass container at a constant relative humidity level of $75 \%$ that was maintained by a saturated aqueous sodium chloride solution at the bottom of the jar. The solar cell samples were placed onto a stage inside the sealed container being exposed to the moist air and without having direct contact with the solution. The humidity chamber was only opened when the samples were taken out for XRD and $J-V$ analysis. As MAPI undergoes a reversible hydration process upon exposure to a highly humid environment, ${ }^{45}$ the hydrated cells were stored under ambient conditions at $\sim 25 \% \mathrm{RH}$ for $4 \mathrm{~h}$ to let the perovskite material stabilize in air at lower humidity prior to the $J$ - $V$ measurements.

Acknowledgements: The authors thank S. Schmidt from the Chemistry Department of LMU Munich for scanning electron microscopy measurements. This project was financed by a grant from the German Federal Ministry of Education and Research (BMBF) under the agreement number 01162525/1. The authors acknowledge funding from the Bavarian Collaborative Research Program "Solar Technologies Go Hybrid" (SolTech), the Center for NanoScience (CeNS), and the DFG Excellence Cluster "Nanosystems Initiative Munich” (NIM). P.D. acknowledges support from the European Union through the award of a Marie Curie Intra-European Fellowship.

Supporting Information available: Additional XRD patterns, XPS spectra, details on the GIWAXS analysis, further optical characterization and $J-V$ measurements. This material is available free of charge via the Internet at http://pubs.acs.org.

Conflict of Interest: The authors declare no competing financial interests. 


\section{REFERENCES}

1. Green, M. A.; Ho-Baillie, A.; Snaith, H. J. The Emergence of Perovskite Solar Cells. Nature Photon. 2014, 8, 506-514.

2. Park, N.-G. Perovskite Solar Cells: An Emerging Photovoltaic Technology. Mater. Today 2015, $18,65-72$.

3. Ponseca, C. S.; Savenije, T. J.; Abdellah, M.; Zheng, K.; Yartsev, A.; Pascher, T.; Harlang, T.; Chabera, P.; Pullerits, T.; Stepanov, A.; Wolf, J.-P.; Sundström, V. Organometal Halide Perovskite Solar Cell Materials Rationalized: Ultrafast Charge Generation, High and Microsecond-Long Balanced Mobilities, and Slow Recombination. J. Am. Chem. Soc. 2014, 136, 5189-5192.

4. Wehrenfennig, C.; Eperon, G. E.; Johnston, M. B.; Snaith, H. J.; Herz, L. M. High Charge Carrier Mobilities and Lifetimes in Organolead Trihalide Perovskites. Adv. Mater. 2014, 26, 1584-1589.

5. Dong, Q.; Fang, Y.; Shao, Y.; Mulligan, P.; Qiu, J.; Cao, L.; Huang, J. Electron-Hole Diffusion Lengths $>175 \mathrm{mM}$ in Solution Grown CH3NH3PbI3 Single Crystals. Science 2015.

6. Shi, D.; Adinolfi, V.; Comin, R.; Yuan, M.; Alarousu, E.; Buin, A.; Chen, Y.; Hoogland, S.; Rothenberger, A.; Katsiev, K.; Losovyj, Y.; Zhang, X.; Dowben, P. A.; Mohammed, O. F.; Sargent, E. H.; Bakr, O. M. Low Trap-State Density and Long Carrier Diffusion in Organolead Trihalide Perovskite Single Crystals. Science 2015, 347, 519-522.

7. Stranks, S. D.; Eperon, G. E.; Grancini, G.; Menelaou, C.; Alcocer, M. J. P.; Leijtens, T.; Herz, L. M.; Petrozza, A.; Snaith, H. J. Electron-Hole Diffusion Lengths Exceeding 1 Micrometer in an Organometal Trihalide Perovskite Absorber. Science 2013, 342, 341344.

8. Green, M. A.; Emery, K.; Hishikawa, Y.; Warta, W.; Dunlop, E. D. Solar Cell Efficiency Tables (Version 45). Prog. Photovolt. Res. Appl. 2015, 23, 1-9.

9. Docampo, P.; Hanusch, F. C.; Stranks, S. D.; Döblinger, M.; Feckl, J. M.; Ehrensperger, M.; Minar, N. K.; Johnston, M. B.; Snaith, H. J.; Bein, T. Solution Deposition-Conversion 
for Planar Heterojunction Mixed Halide Perovskite Solar Cells. Adv. Energy Mater. 2014, 4, n/a-n/a.

10. Nie, W.; Tsai, H.; Asadpour, R.; Blancon, J.-C.; Neukirch, A. J.; Gupta, G.; Crochet, J. J.; Chhowalla, M.; Tretiak, S.; Alam, M. A.; Wang, H.-L.; Mohite, A. D. High-Efficiency Solution-Processed Perovskite Solar Cells with Millimeter-Scale Grains. Science 2015, $347,522-525$.

11. Wu, Y.; Islam, A.; Yang, X.; Qin, C.; Liu, J.; Zhang, K.; Peng, W.; Han, L. Retarding the Crystallization of Pbi2 for Highly Reproducible Planar-Structured Perovskite Solar Cells Via Sequential Deposition. Energy. Environ. Sci. 2014, 7, 2934-2938.

12. Jeon, N. J.; Noh, J. H.; Kim, Y. C.; Yang, W. S.; Ryu, S.; Seok, S. I. Solvent Engineering for High-Performance Inorganic-Organic Hybrid Perovskite Solar Cells. Nat. Mater. 2014, 13, 897-903.

13. Yang, W. S.; Noh, J. H.; Jeon, N. J.; Kim, Y. C.; Ryu, S.; Seo, J.; Seok, S. I. HighPerformance Photovoltaic Perovskite Layers Fabricated through Intramolecular Exchange. Science 2015, 348, 1234-1237.

14. Ahn, N.; Son, D.-Y.; Jang, I.-H.; Kang, S. M.; Choi, M.; Park, N.-G. Highly Reproducible Perovskite Solar Cells with Average Efficiency of 18.3\% and Best Efficiency of $19.7 \%$ Fabricated Via Lewis Base Adduct of Lead(Ii) Iodide. J. Am. Chem. Soc. 2015, 137, 86968699.

15. Sha, W. E. I.; Ren, X.; Chen, L.; Choy, W. C. H. The Efficiency Limit of CH3NH3PbI3 Perovskite Solar Cells. Appl. Phys. Lett. 2015, 106, 221104.

16. Zhao, J.; Wang, A.; Altermatt, P. P.; Wenham, S. R.; Green, M. A. 24\% Efficient Perl Silicon Solar Cell: Recent Improvements in High Efficiency Silicon Cell Research. Sol. Energy Mater. Sol. Cells 1996, 41, 87-99.

17. Zhou, H. P.; Chen, Q.; Li, G.; Luo, S.; Song, T. B.; Duan, H. S.; Hong, Z. R.; You, J. B.; Liu, Y. S.; Yang, Y. Interface Engineering of Highly Efficient Perovskite Solar Cells. Science 2014, 345, 542-546.

18. Li, Y.; Zhao, Y.; Chen, Q.; Yang, Y.; Liu, Y.; Hong, Z.; Liu, Z.; Hsieh, Y.-T.; Meng, L.; Li, Y.; Yang, Y. Multifunctional Fullerene Derivative for Interface Engineering in Perovskite Solar Cells. J. Am. Chem. Soc. 2015, 137, 15540-15547. 
19. Jeng, J.-Y.; Chen, K.-C.; Chiang, T.-Y.; Lin, P.-Y.; Tsai, T.-D.; Chang, Y.-C.; Guo, T.-F.; Chen, P.; Wen, T.-C.; Hsu, Y.-J. Nickel Oxide Electrode Interlayer in CH3NH3PbI3 Perovskite/PCBM Planar-Heterojunction Hybrid Solar Cells. Adv. Mater. 2014, 26, 41074113.

20. Seo, J.; Park, S.; Chan Kim, Y.; Jeon, N. J.; Noh, J. H.; Yoon, S. C.; Seok, S. I. Benefits of Very Thin PCBM and LiF Layers for Solution-Processed p-i-n Perovskite Solar Cells. Energy. Environ. Sci. 2014, 7, 2642-2646.

21. Malinkiewicz, O.; Yella, A.; Lee, Y. H.; Espallargas, G. M.; Graetzel, M.; Nazeeruddin, M. K.; Bolink, H. J. Perovskite Solar Cells Employing Organic Charge-Transport Layers. Nature Photon. 2014, 8, 128-132.

22. Lee, M. M.; Teuscher, J.; Miyasaka, T.; Murakami, T. N.; Snaith, H. J. Efficient Hybrid Solar Cells Based on Meso-Superstructured Organometal Halide Perovskites. Science 2012, 338, 643-647.

23. Heo, J. H.; Im, S. H.; Noh, J. H.; Mandal, T. N.; Lim, C.-S.; Chang, J. A.; Lee, Y. H.; Kim, H.-j.; Sarkar, A.; NazeeruddinMd, K.; Gratzel, M.; Seok, S. I. Efficient Inorganic-Organic Hybrid Heterojunction Solar Cells Containing Perovskite Compound and Polymeric Hole Conductors. Nature Photon. 2013, 7, 486-491.

24. Docampo, P.; Ball, J. M.; Darwich, M.; Eperon, G. E.; Snaith, H. J. Efficient Organometal Trihalide Perovskite Planar-Heterojunction Solar Cells on Flexible Polymer Substrates. Nat. Commun. 2013, 4.

25. Mitzi, D. B.; Wang, S.; Feild, C. A.; Chess, C. A.; Guloy, A. M. Conducting Layered Organic-Inorganic Halides Containing $<110>$-Oriented Perovskite Sheets. Science 1995, 267, 1473-1476.

26. Mitzi, D. B. Templating and Structural Engineering in Organic-Inorganic Perovskites. $J$. Chem. Soc., Dalton Trans. 2001, 1-12.

27. Cheng, Z.; Lin, J. Layered Organic-Inorganic Hybrid Perovskites: Structure, Optical Properties, Film Preparation, Patterning and Templating Engineering. CrystEngComm 2010, 12, 2646-2662.

28. Yangui, A.; Garrot, D.; Lauret, J. S.; Lusson, A.; Bouchez, G.; Deleporte, E.; Pillet, S.; Bendeif, E. E.; Castro, M.; Triki, S.; Abid, Y.; Boukheddaden, K. Optical Investigation of 
Broadband White-Light Emission in Self-Assembled Organic-Inorganic Perovskite (C6h11nh3)2pbbr4. J. Phys. Chem. C 2015, 119, 23638-23647.

29. Wu, X.; Trinh, M. T.; Niesner, D.; Zhu, H.; Norman, Z.; Owen, J. S.; Yaffe, O.; Kudisch, B. J.; Zhu, X. Y. Trap States in Lead Iodide Perovskites. J. Am. Chem. Soc. 2015, 137, 2089-2096.

30. Calabrese, J.; Jones, N. L.; Harlow, R. L.; Herron, N.; Thorn, D. L.; Wang, Y. Preparation and Characterization of Layered Lead Halide Compounds. J. Am. Chem. Soc. 1991, 113, 2328-2330.

31. Cao, D. H.; Stoumpos, C. C.; Farha, O. K.; Hupp, J. T.; Kanatzidis, M. G. 2d Homologous Perovskites as Light-Absorbing Materials for Solar Cell Applications. J. Am. Chem. Soc. 2015, 137, 7843-7850.

32. Smith, I. C.; Hoke, E. T.; Solis-Ibarra, D.; McGehee, M. D.; Karunadasa, H. I. A Layered Hybrid Perovskite Solar-Cell Absorber with Enhanced Moisture Stability. Angew. Chem. Int. Ed. 2014, 53, 11232-11235.

33. Saliba, M.; Tan, K. W.; Sai, H.; Moore, D. T.; Scott, T.; Zhang, W.; Estroff, L. A.; Wiesner, U.; Snaith, H. J. Influence of Thermal Processing Protocol Upon the Crystallization and Photovoltaic Performance of Organic-Inorganic Lead Trihalide Perovskites. J. Phys. Chem. C 2014, 118, 17171-17177.

34. Huang, Y.-C.; Tsao, C.-S.; Cho, Y.-J.; Chen, K.-C.; Chiang, K.-M.; Hsiao, S.-Y.; Chen, C.-W.; Su, C.-J.; Jeng, U. S.; Lin, H.-W. Insight into Evolution, Processing and Performance of Multi-Length-Scale Structures in Planar Heterojunction Perovskite Solar Cells. Sci. Rep. 2015, 5, 13657.

35. Tan, K. W.; Moore, D. T.; Saliba, M.; Sai, H.; Estroff, L. A.; Hanrath, T.; Snaith, H. J.; Wiesner, U. Thermally Induced Structural Evolution and Performance of Mesoporous Block Copolymer-Directed Alumina Perovskite Solar Cells. ACS Nano 2014, 8, 47304739.

36. Zhang, S.; Lanty, G.; Lauret, J.-S.; Deleporte, E.; Audebert, P.; Galmiche, L. Synthesis and Optical Properties of Novel Organic-Inorganic Hybrid Nanolayer Structure Semiconductors. Acta Mater. 2009, 57, 3301-3309.

37. Nobuaki, K. Stability of ( C6H5C2H4NH3)2Pb(BrXI4-X) Mixed Crystals. Jpn. J. Appl. Phys. 1997, 36, 6876. 
38. Ahmad, S.; Kanaujia, P. K.; Beeson, H. J.; Abate, A.; Deschler, F.; Credgington, D.; Steiner, U.; Prakash, G. V.; Baumberg, J. J. Strong Photocurrent from Two-Dimensional Excitons in Solution-Processed Stacked Perovskite Semiconductor Sheets. ACS Appl. Mater. Interfaces 2015, 7, 25227-25236.

39. Zhang, Y.; Liu, M.; Eperon, G. E.; Leijtens, T. C.; McMeekin, D.; Saliba, M.; Zhang, W.; de Bastiani, M.; Petrozza, A.; Herz, L. M.; Johnston, M. B.; Lin, H.; Snaith, H. J. Charge Selective Contacts, Mobile Ions and Anomalous Hysteresis in Organic-Inorganic Perovskite Solar Cells. Materials Horizons 2015, 2, 315-322.

40. Juarez-Perez, E. J.; Wußler, M.; Fabregat-Santiago, F.; Lakus-Wollny, K.; Mankel, E.; Mayer, T.; Jaegermann, W.; Mora-Sero, I. Role of the Selective Contacts in the Performance of Lead Halide Perovskite Solar Cells. J. Phys. Chem. Lett. 2014, 5, 680-685.

41. Eames, C.; Frost, J. M.; Barnes, P. R. F.; O/'Regan, B. C.; Walsh, A.; Islam, M. S. Ionic Transport in Hybrid Lead Iodide Perovskite Solar Cells. Nat. Commun. 2015, 6.

42. Unger, E. L.; Hoke, E. T.; Bailie, C. D.; Nguyen, W. H.; Bowring, A. R.; Heumuller, T.; Christoforo, M. G.; McGehee, M. D. Hysteresis and Transient Behavior in Current-Voltage Measurements of Hybrid-Perovskite Absorber Solar Cells. Energy. Environ. Sci. 2014, 7, 3690-3698.

43. Snaith, H. J.; Abate, A.; Ball, J. M.; Eperon, G. E.; Leijtens, T.; Noel, N. K.; Stranks, S. D.; Wang, J. T.-W.; Wojciechowski, K.; Zhang, W. Anomalous Hysteresis in Perovskite Solar Cells. J. Phys. Chem. Lett. 2014, 5, 1511-1515.

44. Meloni, S.; Moehl, T.; Tress, W.; Franckevicius, M.; Saliba, M.; Lee, Y. H.; Gao, P.; Nazeeruddin, M. K.; Zakeeruddin, S. M.; Rothlisberger, U.; Graetzel, M. Ionic Polarization-Induced Current-Voltage Hysteresis in CH3NH3PbX3 Perovskite Solar Cells. Nat Commun 2016, 7.

45. Leguy, A. M. A.; Hu, Y.; Campoy-Quiles, M.; Alonso, M. I.; Weber, O. J.; Azarhoosh, P.; van Schilfgaarde, M.; Weller, M. T.; Bein, T.; Nelson, J.; Docampo, P.; Barnes, P. R. F. Reversible Hydration of CH3NH3PbI3 in Films, Single Crystals, and Solar Cells. Chem. Mater. 2015, 27, 3397-3407.

46. Hao, F.; Stoumpos, C. C.; Liu, Z.; Chang, R. P. H.; Kanatzidis, M. G. Controllable Perovskite Crystallization at a Gas-Solid Interface for Hole Conductor-Free Solar Cells with Steady Power Conversion Efficiency over 10\%. J. Am. Chem. Soc. 2014, 136, 1641116419. 
47. Liu, G.-N.; Shi, J.-R.; Han, X.-J.; Zhang, X.; Li, K.; Li, J.; Zhang, T.; Liu, Q.-S.; Zhang, Z.-W.; Li, C. A Comparison Study of Aliphatic and Aromatic Structure Directing Agents Influencing the Crystal and Electronic Structures, and Properties of Iodoplumbate Hybrids: Water Induced Structure Conversion and Visible Light Photocatalytic Properties. Dalton Trans. 2015, 44, 12561-12575.

48. Li, Y. Y.; Lin, C. K.; Zheng, G. L.; Cheng, Z. Y.; You, H.; Wang, W. D.; Lin, J. Novel < 110>-Oriented Organic-Inorganic Perovskite Compound Stabilized by N-(3Aminopropyl)Imidazole with Improved Optical Properties. Chem. Mater. 2006, 18, 34633469.

49. Xiao, M.; Huang, F.; Huang, W.; Dkhissi, Y.; Zhu, Y.; Etheridge, J.; Gray-Weale, A.; Bach, U.; Cheng, Y.-B.; Spiccia, L. A Fast Deposition-Crystallization Procedure for Highly Efficient Lead Iodide Perovskite Thin-Film Solar Cells. Angew. Chem. 2014, 126, 10056-10061.

50. Snaith, H. J. How Should You Measure Your Excitonic Solar Cells? Energy. Environ. Sci. 2012, 5, 6513-6520. 